\title{
ANÁLISE CRÍTICA: UM ESTUDO DA CONVERSAÇÃO DO FANDOM DO GRUPO DE K-POP BTS NO TWITTER
}

\author{
Critical analysis: a study of the k-pop BTS group fandom conversation on \\ Twitter
}
Análisis crítico: un estudio de la conversación del grupo k-pop BTS fandom en Twitter

Carlos Renan Samuel Sanchotene Professor dos cursos de Jornalismo e Publicidade e Propaganda - Universidade do Estado de Minas Gerais carlos_sanchotene@yahoo.com.br

Camila Almeida e Silva Jornalista- Universidade do Estado de Minas Gerais camialmeida98@gmail.com

\section{Resumo}

Busca-se estudar de que forma ocorre a conversação entre o fandom brasileiro do grupo de $k$ pop BTS na rede social Twitter. A pesquisa enquadra-se na categoria de hashtag studies e seu processo metodológico foi realizado a partir da Análise Crítica (ROGERS, 2018), que busca identificar o engajamento nas redes sociais digitais a partir de métricas que se baseiam nas seguintes categorias: voz dominante, preocupação, comprometimento, posicionamento e alinhamento. Foi analisada a conversação entre o fandom brasileiro a partir da hashtag \#ArmyHelpthePlanet impulsionada pelos fãs no segundo semestre de 2019. Entre os resultados, concluiu-se que o fandom utiliza o Twitter como uma rede que ressignifica outros espaços transformando-se em uma participação política e cívica no seio da comunidade.

Palavras-chave: Análise Crítica. Fandom. Twitter.

\begin{abstract}
We seek to study how the conversation between the Brazilian fandom of the k-pop group BTS occurs on the social network Twitter. The research falls into the category of hashtag studies and its methodological process was carried out based on Critical Analysis (ROGERS, 2018), which seeks to identify engagement in digital social networks based on metrics based on the following categories: dominant voice, concern, commitment, positioning and alignment. The conversation between the Brazilian fandom was analyzed from the hashtag \#ArmyHelpthePlanet driven by fans in the second half of 2019. Among the results, it was concluded that fandom uses Twitter as a network that gives new meaning to other spaces, transforming itself into political and civic participation within the community.
\end{abstract}

Key words: Critical Analysis. Fandom. Twitter. 


\section{Resumen}

Buscamos estudiar cómo se produce la conversación entre el fandom brasileño del grupo Kpop BTS en la red social Twitter. La investigación cae en la categoría de estudios de hashtag y su proceso metodológico se realizó en base al Análisis Crítico (ROGERS, 2018), que busca identificar la participación en las redes sociales digitales basadas en métricas basadas en las siguientes categorías: voz dominante, preocupación, compromiso, posicionamiento y alineación. La conversación entre el fandom brasileño se analizó por medio de la hashtag \#ArmyHelpthePlanet impulsado por los fanáticos en la segunda mitad de 2019. Entre los resultados, se concluyó que el fandom utiliza Twitter como una red que da un nuevo significado a otros espacios, transformándose en participación política y cívica dentro de la comunidad.

Palabras clave: Análisis Crítico. Fandom. Twitter.

\section{INTRODUÇÃO}

O k-pop é um gênero musical de origem sul-coreana e seu estilo é, hoje, dominado principalmente pelo grupo BTS que estreou em 2013. O grupo constituído por sete cantores do sexo masculino vem ganhando destaque principalmente no mercado musical internacional ${ }^{1}$. O grupo quebra inúmeros recordes diariamente e possui, hoje, algumas conquistas para a indústria sul-coreana. Esteve entre os álbuns mais vendidos na parada Top 100 da Billboard $^{2}$, e atualmente possui o recorde de vídeo com mais visualizações nas primeiras $24 \mathrm{~h}$ horas no Youtube . $^{3}$

O BTS utiliza as redes digitais e mobiliza diversos fandoms (MARTINO, 2014) pelo mundo. E, a rede social onde percebemos maior engajamento é o Twitter, pois o grupo possui, atualmente, mais de 20 milhões de seguidores, e diariamente postam fotos, vídeos e realizam interações instantâneas com os fãs. Essa troca contínua faz com que o grupo estabeleça uma relação de proximidade entre ídolo e fã. E, principalmente, faz com que estejam sempre em destaque na mídia.

O grupo BTS também se faz presente em causas sociais, e com a ajuda dos fãs faz com que esses movimentos chamem atenção e conscientizem as pessoas. É o caso da sua parceria com a UNICEF (Fundo das Nações Unidas para a Infância), que tem como intuito promover a defesa dos direitos das crianças, ajudar a dar resposta às suas necessidades e contribuir para o

\footnotetext{
${ }^{1}$ O grupo BTS foi escolhido como artista do ano de 2020 pela revista norte-americana Time.

${ }^{2}$ De acordo com ranking divulgado pela Billboard. Disponível em: https://t.co/ueLxhViyfK?amp=1. Acesso em: 14 ago. 2020.

${ }^{3}$ De acordo com o site Youtube. Disponível em: https://www.youtube.com/watch?v=GAWCqavx5J4. Acesso em: 14 ago. 2020.
} 
seu desenvolvimento. O BTS se associou a UNICEF para iniciar a campanha Love Myself que busca apoiar os esforços da organização para acabar com a violência. Juntamente com seu fandom conseguiu arrecadar US\$ 1 milhão de dólares para ajudar na campanha.

Diante desse contexto, buscamos estudar de que forma ocorre a conversação entre o fandom brasileiro do grupo BTS na rede social Twitter. Entre os objetivos específicos buscamos identificar as apropriações feitas pelo fandom no Twitter; identificar quem são os protagonistas que atingiram uma maior audiência, quais temáticas estão relacionadas ao grupo k-pop; que perfis mais colaboram para a discussão e propagação das atividades do grupo; quais os principais posicionamentos dos usuários e que discussões ocorrem em paralelo.

Assim, apresentamos uma discussão sobre a cultura dos fandoms, ativismo digital, conversação e engajamento. Logo após, apresentamos o percurso metodológico a partir da Análise Crítica (ROGERS, 2018). A proposta metodológica consiste em uma classificação de hashtags em cinco categorias que visam analisar modos de engajamento por parte daqueles usuários que produzem conteúdos na rede. As cinco categorias propostas pelo autor são: voz dominante, preocupação, comprometimento, posicionamento e alinhamento. Assim, apresentamos a hashtag \#ArmyHelpthePlanet para compreender a conversação estabelecida pelo fandom. A escolha da hashtag aconteceu porque durante o mês de agosto de 2019 o Brasil foi marcado por queimadas e aumento do desmatamento da Floresta Amazônica levando os fãs do grupo a discutir o tema nas redes digitais. Dessa maneira, trabalhamos o desenvolvimento da análise, que foi realizada com base em dados recolhidos no aplicativo online Twitonomy. Entre os resultados, concluímos que o fandom utiliza o Twitter como uma rede que ressignifica outros espaços transformando-se em uma participação política e cívica no seio da comunidade.

\section{CULTURA DOS FANDOMS}

O termo fandom pode ser descrito como um conjunto de pessoas que são fãs de um mesmo artista. Ou seja, o fã é o indivíduo que admira uma figura pública, geralmente do mundo do espetáculo, uma pessoa que nutre admiração por alguém ou alguma coisa. "Na concepção contemporânea, um fã geralmente se relaciona com produtos da mídia, como séries de TV, filmes, livros ou games como um especialista, conhecendo seu objeto de adoração em detalhes" (MARTINO, 2014, p. 157).

Mesquita Júnior (2015) afirma que o consumo midiático faz parte de todo fandom, 
afinal é ele quem divulga e sacia a sede dos fãs por novos bens culturais do seu ídolo. Enquanto a comunidade é todo aquele fandom, que se reúne em algum lugar, seja ele online ou offline sendo assim a hierarquia seria a distinção de fãs dentro de um mesmo fandom.

De acordo com Jenkins (2009), os fãs sempre foram os primeiros a se adaptar às tecnologias de mídia; a fascinação pelos universos ficcionais muitas vezes inspira novas formas de produção cultural. "Os fãs são o segmento mais ativo do público das mídias, aquele que se recusa a simplesmente a aceitar o que recebe, insistindo no direito de se tornar um participante pleno. Nada disso é novo. O que mudou foi à visibilidade da cultura dos fãs" (JENKINS, 2009, p. 188).

Na visão de Martino (2014), nem todo mundo que gosta de um programa de TV ou livro pode ser descrito como fã. Embora seja difícil estabelecer uma fronteira rígida, o que define o fã em relação ao público comum é o seu grau de envolvimento com o produto cultural. Jenkins, Ford e Green (2014, p. 210) classificam o fandom como "[...] um tipo de coletividade (no qual eles agem como comunidades em vez de indivíduos) e conectividade (no qual seu poder é ampliado por seu acesso às comunicações ligadas em rede)". Segundo os autores os membros de minorias ou diferentes grupos de afinidades estão vinculados por meio de "sociabilidade" e "identidade" compartilhadas, bem como procuram "direcionar atenção" por meio de suas ações on-line.

Araújo (2015, p.74) afirma que para além do "número de usuários, leitores e interessados que se alcança é importante que o conteúdo gerado obtenha o mínimo de entrosamento e interação do público e com o público". Sendo assim, o engajamento pode ser visto como uma audiência com qualidade uma vez que indica uma 'reação' do usuário frente ao conteúdo. "As medidas de engajamento são os principais indicadores de desempenho seja de sucesso ou falha das campanhas de marketing digital" (SILVA, 2013, apud ARAÚJO, 2015, p.74). Então, o número de vezes em que um artigo é compartilhado, os comentários e recomendações de leitura que recebe, ou o número de vezes que um tweet é retweetado no Twitter, são exemplos de medidas de engajamento (ARAÚJO, 2015).

Para Curi (2010), os fãs são organizados em uma espécie de sociedade alternativa, que adquire características de uma sociedade complexa e organizada. Sendo, assim, eles trocam referências, interesses e um senso comum de identidade que faz com que tenham a sensação de fazerem parte de um grande grupo, em que todos compartilham o mesmo interesse. Assim, possuem afinidades.

Martino (2014) reforça que a cultura dos fãs altera, entre outros elementos, as relações 
entre as indústrias produtoras do entretenimento e seus públicos. E a participação online constante, os debates a respeito de uma série ou mesmo a publicação de opiniões críticas, muitas vezes, alcançam os espaços de produção. Assim, eventualmente podem alterar tramas, indicar erros ou imprecisões, e até mesmo, estabelecer linhas paralelas ao canon $^{4}$.

Dentre as várias atividades realizadas por fãs, Martino (2014) ressalta que entre elas está a troca de informações com outros fãs, a participação de encontros e eventos, compartilhar novidades e materiais, entre outros. $\mathrm{O}$ autor afirma que manter contato com os demais é fundamental para alimentar o fandom. E, a partir das mídias digitais e da internet, essas interações e conexões potencializaram a cultura dos fãs.

Para Martino (2014), a cultura dos fãs mostrou toda a possibilidade de uma audiência produtiva, que não apenas se articula com os produtos culturais disponíveis, mas também desenvolve suas próprias versões paralelas de maneira criativa. Dentro dessa perspectiva, o autor cita como exemplo as fanart - desenhos, pinturas ou obras criadas pelos próprios fãs. As fanarts dentro do k-pop são muito comuns, e é possível encontrar uma variedade delas, cada qual focando em diferentes traços e cores nos desenhos. Dessa maneira, é possível perceber que o fã mudou muito nos últimos anos. Ele produz através do seu consumo, cria sua identidade e seu estilo de vida, além de usar esses novos sentidos para desenvolver produtos próprios. "Os fãs não criaram apenas uma nova cultura, mas fizeram surgir um novo mercado" (CURI, 2010, p. 5).

Segundo Martino (2014), o olhar se voltou para compreender como os indivíduos e grupos se relacionavam com esses produtos, os articulavam com suas vidas, ganhavam novos significados. O autor ressalta que no caso especial dos fãs, isso significou perceber que, mais do que um grupo de interessados em filmes ou bandas, eles desenvolviam seu próprio circuito cultural e se tornavam uma audiência produtiva.

As principais práticas de consumo dos fãs e interações entre fandoms acontecem, atualmente, por meio das redes digitais que permitem ao fã compartilhar conteúdos, vídeos, fotos e informações sobre determinado interesse e interagir com outras pessoas que possuem interesses comuns. Tais práticas acabam adquirindo, na maioria das vezes, formas de ativismo digital. (passagem para próximo tópico)

\footnotetext{
${ }^{4}$ Segundo Martino (2014), canon seria os elementos "oficiais" de uma trama.
} 


\section{ATIVISMO DIGITAL: CONVERSAÇÃO E ENGAJAMENTO}

O ciberativismo consiste na utilização da internet por grupos, politicamente motivados, que buscam difundir informações e reivindicações sem qualquer elemento intermediário com o objetivo de buscar apoio, debater e trocar informação, organizar e mobilizar indivíduos para ações, dentro e fora da rede. De modo geral, o ciberativismo é tratado como a forma de utilização radical das ferramentas da rede, "onde indivíduos e grupos têm suas ações políticas potencializadas pelos ambientes midiáticos e descentralizadas na internet" (ARAÚJO, 2011, p. 3).

Segundo Diniz e Caleiro (2011), esse conceito pode ser visto como uma forma alternativa ao monopólio exercido pelos meios de comunicação de massa e ao controle sóciodiscursivo que, segundo determinadas correntes, alegadamente exercem. $\mathrm{O}$ autor relata que o ativismo encontrado na web 2.0 é um instrumento democrático, potencialmente expansivo, capaz de incitar debates de temas possíveis da mídia e outros já abordados, porém sem a rigidez de controles ou filtros na informação por estes apresentados.

Atualmente, é possível perceber vários acontecimentos que tomaram uma proporção grande graças as dinâmicas das redes digitais. Um exemplo encontrado em termos de ativismo digital vem das comunidades de fandoms. Segundo Jenkins, Green e Ford (2014), essas comunidades abraçaram as tecnologias conforme foram aparecendo, principalmente quando esses recursos lhes ofereciam novos meios de interação. Citando a popularidade do Twitter, os autores afirmam que a rede digital facilita os tipos de compartilhamento de recursos, de conversações e de coordenação que as comunidades de fãs vêm usando há muito tempo.

Para Recuero e Zago (2009), no Twitter, as conexões vão muito longe, pois além de formar as redes pela conversação, é possível formar uma rede de contatos na qual jamais houve qualquer tipo de interação recíproca. E nessa conexão, embora não recíproca, pode dar ao ator acesso a determinados valores sociais que os mesmos não teriam acesso de outra forma, tais como determinados tipos de informações. (explicitar com o objeto selecionado articular melhor empiria e teoria)

Com as mobilizações pelas redes digitais, os movimentos sociais também acabam por ganhar ainda mais força. (articular citação) "Portanto, este é um território fértil para a fomentação de assuntos, principalmente no que se refere à percepção sobre a importância para cada um: 6 em cada 10 internautas acreditam que as redes sociais contribuem para a mudança a respeito de algum problema social." (ODORICO, 2016, p. 6). 
Segundo Montardo e Araújo (2013), as redes sociais tendem a proporcionar ao usuário mobilizações ciberativistas como uma forma de comunicação mais horizontalizada na qual engajamento pode ter o significado de visibilidade, seja entre os atores sociais de uma rede ou em muitos casos, visibilidade midiática. "Neste sentido, pode-se considerar que a visibilidade pelo engajamento coletivo busca da na utilização de sites de redes sociais está diretamente ligada a uma participação performática dos indivíduos conectados a um grupo ciberativista" (MONTARDO; ARAÚJO, 2013, p. 484). Os autores afirmam, ainda, que isso seria uma maneira de exibir sua identificação com determinada causa aos usuários nas redes, como forma de persuadi-los a também compartilharem de determinado valor, ampliando assim o alcance da mobilização.

Para Jenkins, Green e Ford (2014), tudo isso sugere maneiras de revisar o conceito de cultura participativa para que reflita a realidade de um ambiente midiático modificado ainda em transformação. Dessa maneira, com a sociedade cada vez mais interativa, as mídias digitais se tornaram um grande elemento para proporcionar essa atuação. Odorico (2016, p.2) reforça que essa configuração "viabiliza mobilizações dos cidadãos no universo on-line por meio do ativismo digital, de modo que a internet pode ser utilizada como um viés transformador da realidade de diversos territórios, ou seja, uma verdadeira democrática e acessível, que pode ser praticada por qualquer pessoa que tem acesso a rede". (diálogo com o objeto)

Jenkins (2009) ressalta que o público ganha poder com as tecnologias e vem ocupando cada vez mais um espaço na intersecção entre os velhos e os novos meios de comunicação, e está exigindo o direito de participar da cultura. $\mathrm{O}$ autor conclui que produtores que não conseguirem fazer as pazes com a nova cultura participativa enfrentarão uma clientela declinante e a diminuição dos lucros. As contendas e as conciliações resultantes irão definir a cultura pública do futuro.

Recuero (2014) aborda que o avanço das redes digitais hoje é uma realidade, visto que muitas dessas redes são vistas como uma ferramenta apropriada simbolicamente para construir o espaço social no cotidiano dos atores, gerando práticas que ressignificam seus usos. A autora enfatiza que dentre essas apropriações está a conversação.

Marcuschi (2006) citado por Recuero (2014, p. 115) define a conversação como "uma interação verbal centrada, que se desenvolve durante o tempo em que dois ou mais interlocutores voltam sua atenção visual e cognitiva para uma tarefa comum". Dessa maneira, observamos a conversação como um evento temporal, com objetivos e, portanto, 
organizada entre dois ou mais atores. Sendo assim, pode-se dizer que a conversação é um fenômeno que foca principalmente as interações orais que ocorrem entre atores em um determinado contexto, com alternância na tomada de turno de fala (RECUERO, 2014).

Apesar de a conversação ser compreendida por um fenômeno falado, nos dias de hoje ela pode ser encontrada principalmente nas redes digitais. Pois, novos usos e sentidos são construídos nas ferramentas de modo a possibilitar que os elementos da conversação, como a interação entre dois ou mais sujeitos, sua organização (a criação e o espalhamento das convenções) e mesmo os contextos sejam divididos pelos participantes. Além disso, as conversações, no espaço dos sites de rede social, também adquirem os contornos associados aos públicos em rede (RECUERO, 2014)

Para a autora, essas conversações expressam a participação de centenas de pessoas, por vezes, com milhares de interações que são acessíveis, de forma assíncrona, por todos os atores. Essa assincronia é que permite que pessoas temporalmente distantes tomem o turno e recuperem as conversações, espalhando-as e fazendo com que migrem entre os grupos e entre os sites de rede social. (diálogo com o objeto)

Abordando a questão da conversação através dos meios digitais, Araújo (2015, p.73) ressalta que a "presença online é o marco inicial de ingresso aos interessados em atingir um público maior e cada vez mais conectado no ambiente web”. O autor destaca que as pessoas tendem a interagir com conteúdos que as interessem, e é comum buscarem algum tipo de filiação com produtores desses conteúdos, como assinar blogs, curtir páginas do Facebook ou seguir no Twitter.

Atualmente, um dos maiores exemplos da força de um fandom na rede é articulado pelos fãs de diversos grupos de k-pop. Esses fãs, em específico, são bastante ativos nas plataformas digitais, principalmente no consumo midiático, nas divulgações e nos recordes de votações online.

\section{MÉTODO}

Esta pesquisa enquadra-se na metodologia de hashtag studies (BRUNS; BURGESS, 2011) e a proposta metodológica foi elaborada a partir da Análise Crítica criada por Richard Rogers (2018). Nesse tipo de análise, as redes sociais digitais são vistas como locais de ações e engajamento. $\mathrm{O}$ autor propõe esse tipo de análise para criticar as métricas de vaidade, que é um termo que captura as métricas de quantidade a partir de curtidas, seguidores, comentários 
nas redes sociais e, sobretudo, apontar "métricas alternativas para medir outras formas de envolvimento com as mídias sociais" (ROGERS, 2018, p. 451, tradução nossa). ${ }^{5}$ Neste sentido, Rogers sugere as métricas de engajamento que se baseiam nas seguintes categorias:

a) Voz dominante: As vozes dominantes estão relacionadas aos perfis com maior engajamento. Ou seja, qual é a voz que atinge a maior audiência? Quais são os tweets mais replicados e favoritados? De acordo com Rogers (2018, p.456, tradução nossa), "a voz dominante capta as fontes consideradas mais impactantes (embora não necessariamente confiáveis) dentro desse espaço". 6

b) Preocupação: A preocupação se refere à temática em debate. "A análise crítica aqui apresentada são registros instantâneos relacionando-se não apenas a quem, mas especificamente, a quem uma questão é motivo de preocupação em um dado momento" (ROGERS, 2018, p. 459, tradução nossa). ${ }^{7}$

c) Comprometimento: O comprometimento refere-se aos usuários que estão mais presentes em um determinado tempo colaborando para a discussão e propagação do assunto em debate. "Por quanto tempo uma questão é motivo de preocupação para os atores? [...] a questão relacionada para o assunto diz respeito à longevidade ou perseverança das preocupações"8 (ROGERS, 2018, p.459, tradução nossa).

d) Posicionamento: Busca identificar qual a posição desses usuários em relação a determinados temas em questão. "Uma análise de posicionamento começa localizando e classificando as escolhas intencionais das palavras-chave utilizadas pelos atores [...] detectando (e significativamente interpretando e traçando) temas que são emitidos pelos atores"9 (ROGERS, 2018, p.461, tradução nossa).

e) Alinhamento: Busca identificar quais discussões ocorrem em paralelo. Segundo Rogers (2018, p.466, tradução nossa), "são palavras-chave ou termos específicos que

\footnotetext{
${ }^{5}$ Texto original: alternative metrics to measure other forms of engagement with social media.

6 Texto original: dominant voice captures the sources considered most impactful (though not necessarily credible) within that issue space.

7 Texto original: The critical analytics presented here are snapshots relating not only to whether but specifically to whom an issue is a matter of concern at a given time.

8 Texto original: For how long is an issue a matter of concern to the actors? [...] the related question for the issue concerns longevity or perseverance.

${ }^{9}$ Texto original: A positioning analysis begins by locating and placing the actors purposive keyword choice [...] it is one of detecting (and meaningfully interpreting and plotting) issue space insertions by actors.
} 
os atores usam quando discutem uma questão. Quando vários atores usam a mesma língua $[. .$.$] eles se alinham" { }^{\prime \prime}$.

Nesse sentido, o autor propõe uma análise alternativa para análise de métricas para mídias sociais digitais a partir desses cinco movimentos. "Análise crítica - projeto de métricas alternativas para mídia social - procura medir o "envolvimento de outra maneira" ou modos de engajamento (além daqueles feitos para métricas de vaidade)” (ROGERS, 2018, p.467, tradução nossa). ${ }^{11}$ Para o autor, essa proposta metodológica busca ver a rede daqueles que emitem conteúdos. Assim, a rede social é produtiva não apenas para si mesma, mas para a análise de engajamento.

Diante das explicações metodológicas, o corpus de análise foi composto da seleção da hasthtag \#ArmyHelpthePlanet e analisada pelo do aplicativo online Twitonomy ${ }^{12}$, que oferece dados específicos de engajamento. A hashtag foi analisada a partir das cinco categorias propostas por Richard Rogers (2018).

\section{ANÁLISE: \#ArmyHelpthePlanet}

O mês de agosto de 2019 foi marcado por queimadas e aumento do desmatamento da Floresta Amazônica no Brasil. Diante desse contexto, ganharam forte repercussão em todo mundo, e ocuparam por um bom tempo do mês de agosto, os trending topics no Twitter do Brasil e do mundo. Assim, os fãs do grupo BTS, se mobilizaram no Twitter e criaram a hashtag \#ArmyHelpThePlanet (Army ajuda o planeta) uma campanha para preservação da região amazônica. A campanha, realizada pelos fãs, buscou conscientizar as pessoas sobre a importância da preservação da natureza, e o perfil oficial da campanha @ARMY_HTP, criado pelo fandom brasileiro, liderou o projeto na rede social, em que divulgava informações e notícias sobre a mobilização. No dia 30 de agosto foi publicado um vídeo com legendas em português, inglês e coreano, visando a atingir e conscientizar os fãs do mundo inteiro.

\#ArmyHelpThePlanet permaneceu entre os assuntos mais comentados do Brasil e do mundo, na última semana de agosto, em especial pela divulgação do vídeo da campanha. Assim, a hashtag foi analisada no dia 21 de agosto de 2019 das 16h52 às 17h17, horário em

\footnotetext{
${ }^{10}$ Texto original: are particular keywords or terms actors use when discussing na issue. When multiple actors use the same language [...] they align.

${ }^{11}$ Texto original: The critical analytics presented here are snapshots relating not only to whether but specifically to whom an issue is a matter of concern at a given time.

12 Disponível em: https://www.twitonomy.com
} 
que a mesma estava em primeiro lugar nos trending topics do Twitter no Brasil, entre os assuntos mais comentados do país. Nesse período foram coletadas 3.008 mensagens extraídas do Twitter, na qual pôde se analisar toda a mobilização do fandom Army em relação ao tema em debate. Como forma de analisar o engajamento e ativismo dos fãs por meio das narrativas surgidas pela criação da hashtag, utilizou-se as métricas da Critical Analysis propostas por Rogers (ano).

\subsection{Voz dominante}

$\mathrm{Na}$ categoria voz dominante consideramos os perfis com maior engajamento, partindo dos tweets mais replicados e favoritados. Dessa maneira, percebemos não só os perfis que obtiveram maior audiência, mas também os conteúdos que foram mais compartilhados dentro da amostra sobre o contexto envolvido a comunidade e o assunto em torno da hashtag em questão.

No quadro 1 abaixo, segue uma lista dos 10 perfis com mais seguidores da amostra:

Quadro 1: Ranking dos perfis com mais seguidores da campanha

* Most influential users

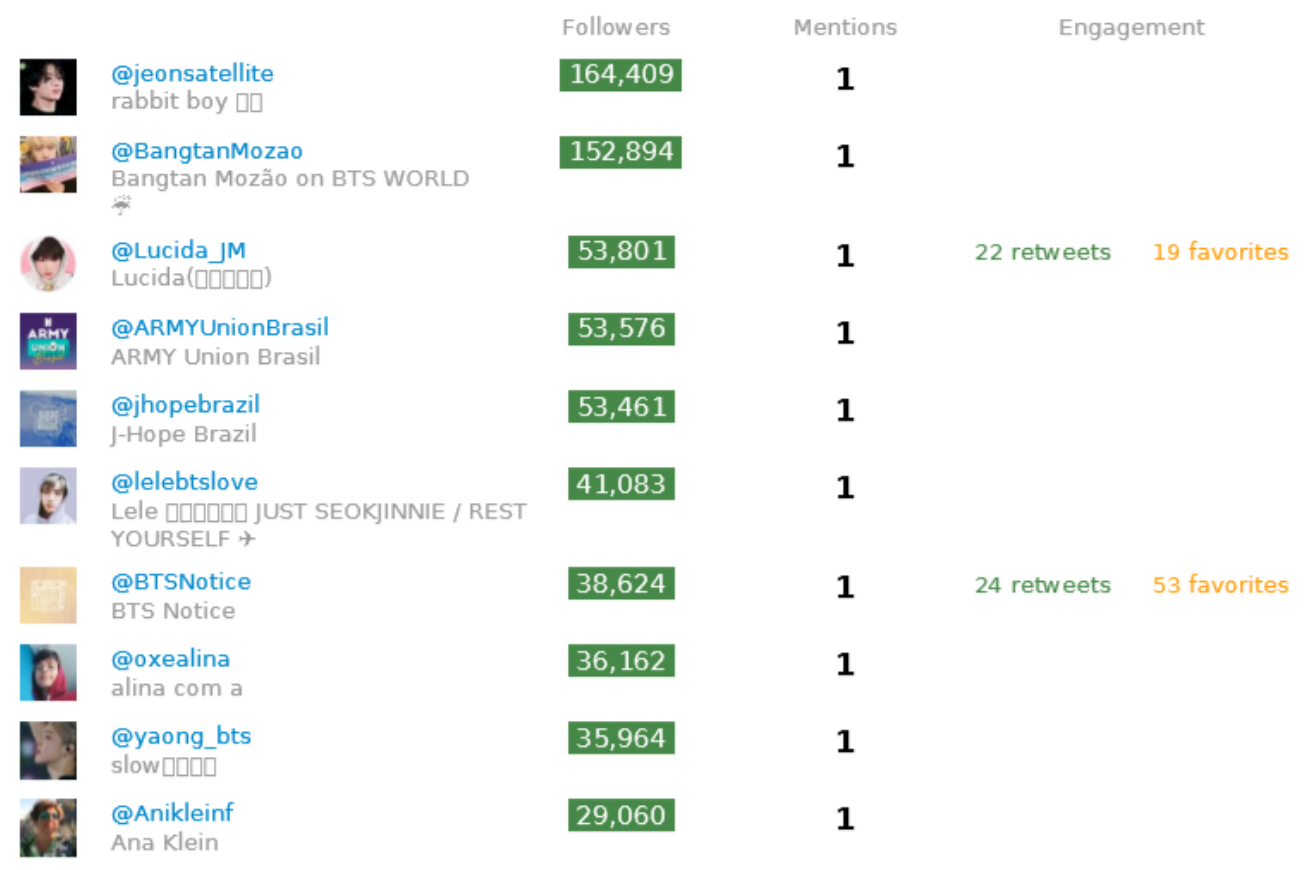

Fonte: aplicativo online Twitonomy 
A partir dos dados recolhidos é possível perceber a evidente predominância dos perfis de fãs brasileiros, em especial de fanbases dedicadas ao grupo BTS. Como os perfis @BangtanMozão, @ArmyUnionBrasil, @BTSNotice, e até a página @JhopeBrasil, dedicada a um integrante específico do grupo. Essas fanbases funcionam como perfis no Twitter com o objetivo de informar os fãs sobre noticiais, informações e curiosidades sobre o grupo.

$\mathrm{Na}$ maioria das vezes são por essas páginas que são feitas as divulgações de projetos relacionados ao artista, por sugestão dos fãs. É de se destacar que a maioria das fanbases brasileiras tem um bom número de seguidores e são muito participativas em relação aos temas em debate.

O perfil oficial do projeto @ARMY_HTP, não aparece entre as 10 páginas com mais seguidores, apesar disso, a conta possuía no dia de divulgação cerca de 14, 9 mil seguidores. Entretanto, o baixo número de seguidores da página não atrapalhou na repercussão da hashtag, visto que seu uso foi impulsionado por diversos outros perfis com maior engajamento e alcance na plataforma, principalmente pelo fato da hashtag estar em alta nos assuntos do momento, o que leva as pessoas a clicarem na mesma e visualizar uma timeline voltada para o tema.

Desse modo, é interessante perceber por meio dos perfis a presença de ativistas internacionais. Isso acontece principalmente pelo engajamento e disseminação que a hashtag atinge, pois o tema surgiu por iniciativa do fandom brasileiro e por causa da sua divulgação permitiu que chegasse aos fãs de diversas partes do mundo.

Como exemplo os perfis@jeonsatellite, @Lucida_JM, @lelebtslove e @yoong_BTS, twitters de fãs dos Estados Unidos, Espanha e até mesmo da Coreia do Sul, que se mobilizaram e ajudaram a divulgar para o fandom de todo o mundo. Isso se relaciona com que Recuero (2014), afirma quando diz que no Twitter as conexões vão ainda mais longe, pois além de formar essas redes pela conversação, é possível formar uma rede de contatos na qual jamais houve qualquer tipo de interação, e pode dar ao autor determinados valores sociais que não estariam tão acessíveis de outras formas, tais como determinados tipos de informações.

Um dos principais elementos na identificação da voz dominante foram os conteúdos que tiveram maior engajamento, ou seja, os posts que foram mais retweetados e favoritados. A maior parte das mensagens estavam relacionadas a forte divulgação que o fandom apresentou e como a mobilização por esse motivo atingiu portais de notícias no Brasil e no mundo, como por exemplo, a matéria publicada na CNN Americana. 
No ranking de reweets recolhidos na amostra, percebemos novamente a presença das fanbases brasileiras de notícias do grupo BTS.Como os perfis@JHSBRAZIL, @BTSNotice e @btsbr_official. Isso acontece principalmente porque esses perfis ativistas muitas vezes são responsáveis por informar o fandom em relação aos temas em debate, e os fãs por sua vez ajudam a divulgar esse conteúdo através dos retweets. Os fãs internacionais também aparecem de maneira ativa ajudando na divulgação do projeto.

Quadro 2 - Ranking dos perfis mais retweetados da campanha

\section{\& Most retweeted tweets}

HSS Jung Hoseok Brasil [REST] @JHSBRAZIL 5:02 PM - 21 Aug 2019 via Twitter for Android - 91 retweets - 158 favorites Open

Vocês têm noção do que é isso ?? A informação do \#ARMYHeloThePlanet chegou na CNN, eu disse CNN!!!! Com certeza o @BTS twt é muito orgulhoso de ter o fandom que teml Não é atoa que o \#BTS e o \#ARMY foram escolhidos como líderes do futuro da sustentabilidade pela ONU! https://t.co/h1Kyht6G6c

Pa Georgina @GeorginaMonse18 5:12 PM - 21 Aug 2019 via Twitter Web App - 27 retweets - 34 favorites Open

2.2. Si no hacemos algo ya,este puede ser nuestro cruel final \#PrayforAmazonas \#ARMYHelpThePlanet https://t.co/d4 DUwu4 wif]

BTS Notice @BTSNotice 5:12 PM - 21 Aug 2019 via Twitter for Android - 24 retweets - 53 favorites Open

[\#ARMYHelpThePlanet] - Pouco a pouco, os meios de comunicação mais influentes estão fazendo anotações e artigos sobre oque está acontecendo na Amazônia. Se você puder marcar a mídia, seja televisão, impressão ou rádio, faça isso. Vamos levantar a voz! [amp.cnn.com/cnn/2019/08/21..

A Lucida(प⿴囗十) @Lucida JM 5:08 PM - 21 Aug 2019 via Twitter for iPhone - 22 retweets - 19 favorites Open

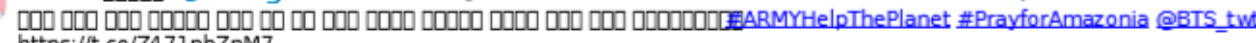
https://t.co/Z47lpbZnM7

- México With Bangtan | W.I.N.G. व[@@MWBUnion 5:00 PM - 21 Aug 2019 via Twitter for Android - 11 retweets - 12 favorites Open INFOT[DBTS twt BTS quienes se hàcen llamar ARMY se están uniendo en Twitter para difundir la noticia de los incendios con más de 10 mil personas usando \#ArmyHeloThePlanet $\mathrm{um}$

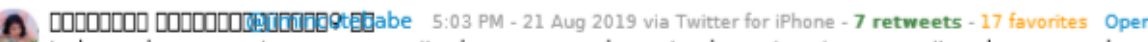

todos podemos aportar con un granito de arena no solamente ahora sino siempre, evitar el consumo de carnes y de plástico en todos los sentidos, el mundo se está muriendo y la principal razón somos nosotros, nunca es tarde para generar un cambio \#PrayforAmazonia \#ArmyHelpThePlanet https://t.co/v696WDjgs6

BTS BRASIL @btsbr official 5:14 PM - 21 Aug 2019 via Twitter for Android - 6 retweets - 25 favorites Open

[D]] Precisamos abordar um assunto muito importante com vocêsł\#ARMYHelpThePlanet \#PrayForAmazonia A nossa amada Amazônia, cheia de vida e conhecida como "pulmầo do mundo", esteve em chamas, com o fogo não só na linda floresta, como também nos animais que habitam nela. (+) https://t.co/Mon5 w3aP85

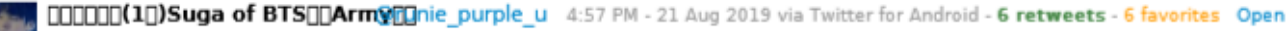

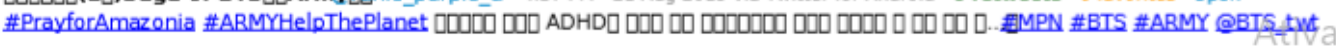

A Georgina @GeorginaMonse18 4:54 PM - 21 Aug 2019 via Twitter Web App - 4 retweets - 5 favorites Open EL PULMON DE LA TIERRA ESTA EN LLAMAS Y LOS GOBIERNOS CREEN QUE NO PASA NADA ,CUANDO SE QUEMO EL CASTILLO DE NOTRE DAME EN 24HRAS YA TENIAN RECAUDACIONES Y LA GENTE Y LOS GOBIERNOS SE PREOCUPARON PERO PORQUE NO HACEN LO MISMO CON EL AMAZONAS \#PrayforAmazonas \#ARMYHelpThePlanet

Fonte: aplicativo online Twitonomy

$\mathrm{Na}$ amostra, nota-se que o RT é a forma mais utilizada para divulgação de um determinado conteúdo. É interessante notar que há uma interação entre os perfis, mesmo que de maneira indireta, pois os mesmos debatem acerca do tema e ajudam a mobilizar mais pessoas em relação a ameaça na Floresta Amazônica. Recuero (2014) aponta que com isso, as conversações tomam outra dimensão, pois são reproduzidas facilmente por outros atores e se 
espalham nas redes entre os diversos grupos. Elas migram e tornam as conversações mais públicas, moldam e expressam opiniões, geram debates e amplificam ideias.

$\mathrm{Na}$ análise referente aos tweets mais favoritados, o conteúdo não apresenta muita diferença em relação aos mais retweetados. Estão presentes nos rankings dos mais favoritados a maioria dos perfis que obtiveram mais retweets em seus posts, como as fanbases brasileiras @JHSBRAZIL, @BTSNotice, e a mexicana @MWBUnion. Nota-se também perfis de fãs mobilizando as pessoas a ajudarem na campanha e informando sobre a situação da Amazônia.

Dessa maneira, percebemos que o Twitter auxilia seus usuários na formação de suas próprias redes, tornando possível que eles tenham um contato "mais direto" uns com os outros, por meio dessas formas de conversação. No caso do ranking dos tweets mais favoritados, apresentam-se informações e reforços sobre o conteúdo da campanha.

\subsection{Preocupação}

Segundo o perfil oficial do projeto no twitter @ ARMY_HTP, o foco principal da conta é passar instruções para os representantes de cada estado do Brasil, mostrando os objetivos a serem trabalhados. O perfil afirma que o principal intuito é promover a união das Armys em todo o mundo para iniciar um movimento que inspire a pessoas a fazerem sua parte em busca de melhorar e preservar o meio ambiente.

No conjunto de tweets coletados na amostra, notamos que não houve predominância de tweets que fugissem do sentido proposto. Sendo assim, houve mais discussões e divulgações do conteúdo da campanha. As temáticas se dividiram em quatro tópicos:

- Sobre a campanha: neste tópico evidenciamos nas mensagens principalmente a divulgação, mobilização e incentivo as pessoas a contribuírem com o projeto.

- Informações sobre a situação da Floresta Amazônica: outro tópico muito mencionado foi notícias referentes ao estado da Amazônia, não só recentes, mas enfatizando como o meio ambiente vem sido prejudicado há anos.

- Apoio: sobre o conteúdo da campanha houve muitas menções elogiando a iniciativa do fandom brasileiro ao começar o projeto.

- Divulgação do fandom Army de outros países: como foi possível observar no ranking dos perfis mais replicados e favoritados, os fãs do grupo BTS de 
diversas partes do mundo se mobilizaram e aderiram a hashtag com o intuito de ajudar os barmys.

\subsection{Comprometimento}

Nesta categoria foram analisados os usuários mais presentes em um determinado tempo, e os que mais colaboraram para a discussão e propagação da campanha. Pela amostra de dados gerada pelo aplicativo foi possível observar os 10 perfis mais ativos no período de tempo presentes no debate.

$\mathrm{Na}$ análise, observamos que todos os perfis que ficaram em destaque são perfis estrangeiros, que atuaram como replicadores de conteúdo. Dessa maneira esses perfis ficaram mais focados em retweetar e favoritar os conteúdos que provinham da hashtag, sendo assim, apesar de não produzirem conteúdo próprio, replicaram muitos tweets envolvendo a campanha e dessa forma também ajudaram a engajar o projeto em si.

Figura 2 - Exemplo de tweet replicado

ใح. kookiee retweetou

Luke Waltham @lukewaltham.20 ago

Lets help our fellow B-ARMYs by supporting \#ARMYHelpThePlanet! The Amazon forest has suffered terrible forest fires which is an awful sign of global warming. We need to do more to save our planet. Make a difference in your community. Go green. Help the Planet. 은?

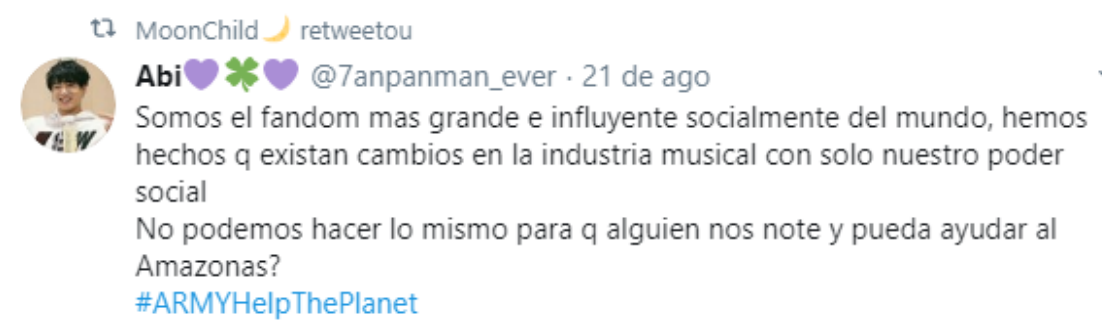

Fonte: aplicativo online Twitonomy

No primeiro exemplo o perfil de uma fã americana, @kookieebima replicou um tweet de uma figura pública, um ativista americano que se mobilizou com a campanha, ajudou a divulgar o projeto e mostrou a importância da ação criada pelo fandom brasileiro. Já em outro exemplo mostra-se o perfil de uma fã argentina, @juliialvarez que retweetou um conteúdo divulgado por outra fã, onde ressaltava que os fãs em todo mundo precisavam aproveitar de 
sua influência e se unir para ajudar a Floresta Amazônica. Esse ponto tem relação com o que Zanetti (2011) afirma ao falar que em termos de redes sociais não basta somente o usuário estar conectado para acessar algum conteúdo e ser "visto", mas essencialmente deve-se compartilhar, o que significar produzir e replicar mais conteúdos, tornando acessível a um grande número de pessoas.

\subsection{Posicionamento}

Em relação à posição dos usuários ao tema em questão, a sua grande maioria se mostrou favorável a campanha \#ArmyHelpThePlanet, criada pelos fãs brasileiros do grupo. A partir do conjunto de dados extraídos pela amostra foram identificados perfis que não só contribuíram para a disseminação do projeto, mas ajudaram a compartilhar informações sobre a situação em que a Amazônia se encontrava. Na figura a seguir observamos um exemplo de posicionamento favorável à campanha e que rendeu uma nova ação promovida pelos fãs: a plantação de mudas de árvores pelo país.

Figura 3 - Exemplo de tweet replicado

\section{.Biazinha SIREN:DAWN @... 30 nov. 19}

Dia de \#ArmyPlantingParty em Paulínia - SP.

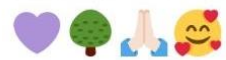

Muito feliz com esse projeto!!

@BTS_twt @ARMY_HTP

\#ARMYHelpThePlanet

\#armyhelptheamazon
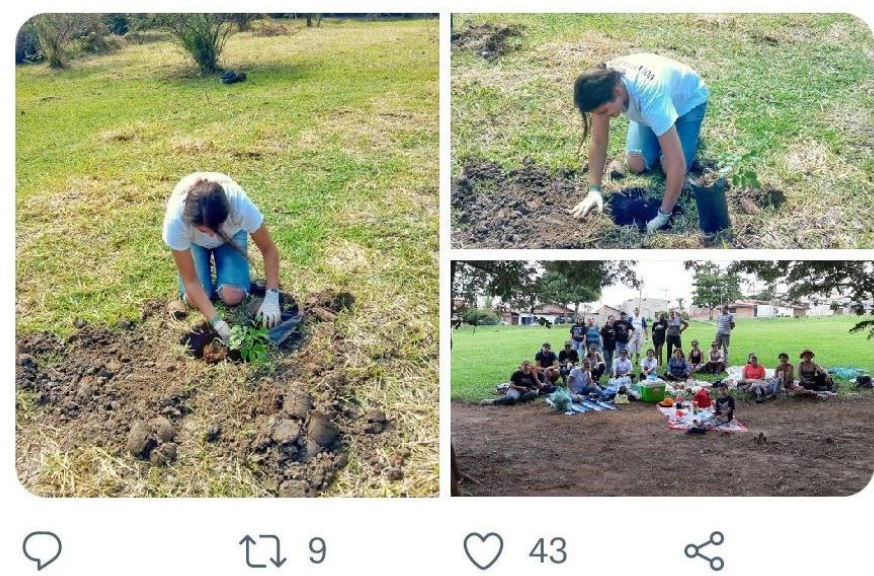

Fonte: Twitter 
É importante destacar que a categoria Posicionamento proposta por Rogers (2018) considera também a colocação da escolha intencional de outras palavras-chave. Trata-se de detectar inserções de questões feita pelos atores, no espaço. No Twitter, quando uma hashtag é atrelada à outra, os atores podem injetar também um contraposicionamento. Segundo o autor, esses são frequentemente considerados como "públicos configurados por hashtags" e são descritos como aqueles que elogiam e apoiam a hashtag em questão, ridicularizam por meio de memes, propagam spams, e praticam "trollagens". Durante a observação em questão, encontramos apenas tweets de apoio à campanha \#ArmyHelpThePlanet.

\subsection{Alinhamento}

Na métrica proposta no alinhamento, observamos quais são as discussões que podem surgir em relação à temática em questão. Foram detectadas quais as hashtags estão envolvidas na discussão e quais foram usadas no mesmo post. Por meio dos dados coletados na amostra identificamos um ranking das hashtags mais utilizadas envolvendo a campanha:

Quadro 3 - Ranking das principais hashtags envolvidas na campanha

$\begin{array}{lc}\text { \# Top hashtags } & \\ \text { \#armyhelptheplanet } & 1,297 \\ \text { \#prayforamazonas } & 428 \\ \text { \#prayforamazonia } & 313 \\ \text { \#army } & 125 \\ \text { \#bts } & 94 \\ \text { \#mpn } & 92 \\ \text { \#amazonia } & 32 \\ \text { \#prayforamazon } & 29 \\ \text { \#prayfortheamazon } & 29 \\ \text { \#btsarmy } & 25\end{array}$

Fonte: aplicativo online Twitonomy

No ranking dos top 10, notamos que a grande maioria das hashtags utilizadas estão relacionada ao tema da campanha (\#armyhelptheplanet, \#prayforamazonas, 
\#prayforamazonia, \#army, \#bts, \#amazonia, \#prayforamazon, \#btsarmy), sendo que todas correspondem a situação da Floresta Amazônia e ao nome do fandom e do grupo, divulgando o projeto dos fãs.

A única hashtag utilizada que não corresponde à temática em si, foi a \#mpn. A tag foi usada junto com as demais por pertencer a uma campanha de votos realizadas pelo Twitter referente à premiação brasileira "Meus Prêmios Nick", do canal Nickelodeon, onde o grupo BTS concorria a fandom do ano.

Percebemos que a maioria das hashtags utilizadas na campanha foram usadas pelos perfis mais ativos. Isso acontece geralmente porque os perfis mais ativos também são os que mais estão compartilhando e divulgando conteúdos constantemente. Como foi visto na métrica do comprometimento, esses usuários ajudam a propagar ainda mais as hashtags.

Essa questão corrobora com o que a autora Zanetti (2011) afirma ao falar que a prática do compartilhamento mantém as redes, pois o ato de propagar os conteúdos favorecem a expansão e a intensidade dos laços fracos justamente porque gera uma grande quantidade e diversidade de conteúdos na rede.

A partir dos dados coletados na amostra podemos identificar que o impacto dos perfis mais ativos também está relacionado ao número de mensagens que os mesmos propagam. $\mathrm{Na}$ utilização da hahtag também é importante notar que muitas vezes várias são usadas no mesmo tweet.

Na campanha "Armyhelptheplanet" foi possível perceber uma concordância entre as temáticas abordadas nas principais hashtags utilizadas. Por ter sido uma campanha que surgiu por meio das notícias e da mobilização das pessoas em relação a situação da Floresta Amazônica, a maioria das hashtags foram \#prayforamazonas, \#prayforamazonia, \#prayforamazon, \#prayfortheamazon, que em tradução literal significa: reze pela Amazônia. 
Figura 4 - Exemplo de hashtags utilizadas na campanha

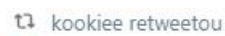
is lack of media coverage. Let's inform the world of what is happening.
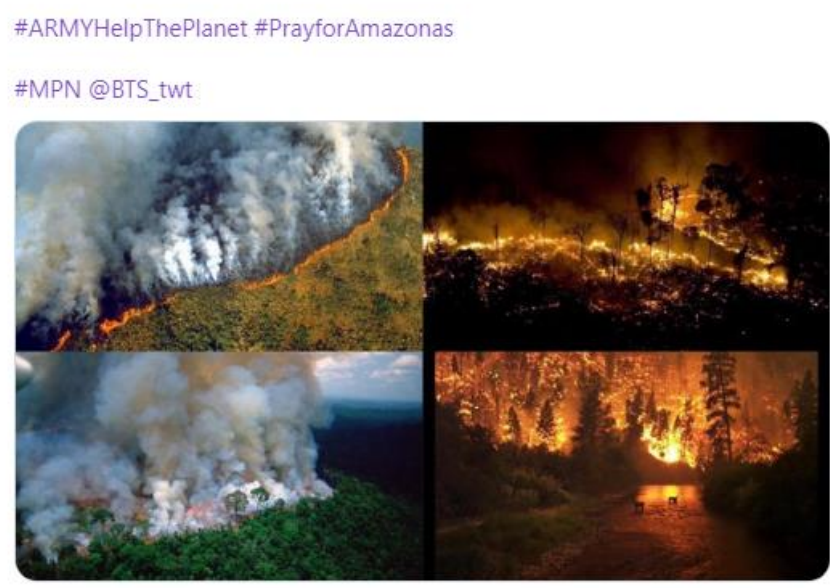

๑ 173 七 5,5 mil $\bigcirc 4,6$ mil $\uparrow$

Fonte: BTS Voting Fam

Apesar de a campanha ter sido criada pelo fandom brasileiro, grande parte dos nomes atribuídos as hashtags recolhidas na amostra foram escritos em inglês, como por exemplo o nome divulgado na campanha \#ArmyHelpThePlanet e \#prayforamazonas. Os $b$-armys muitas vezes também traduziam os conteúdos do português para o inglês e espanhol em suas publicações na rede.

O uso de outras línguas nos tweets e no nome das hashtags, indicam uma forma criada pelos fãs brasileiros de propagar o conteúdo e globalizar a campanha não só aos fãs, mas as pessoas em todo o mundo, para que tomem conhecimento da causa e ajudem a mobilizar o projeto.

\section{CONSIDERAÇÕES FINAIS}

A pesquisa buscou compreender de que forma ocorre a conversação entre os fãs do grupo de k-pop BTS no Twitter. Para tanto, foi analisada a hashtag \#ArmyHeplthePlanet promovida pelo fandom brasileiro no segundo semestre de 2019. Por meio do estudo mostramos como é pertinente estudar os modos de engajamento e como o fandom circula conteúdos na rede para dar visibilidade ao seu ídolo. E, também, ver que nessa prática a rede social é produtiva especialmente para a conversação e mobilização do fandom em si. 
Para desenvolver a parte metodológica, a hashtag foi analisada utilizando-se do aplicativo Twitonomy, sendo uma importante ferramenta para extrair dados quantitativos e qualitativos no Twitter. Para entender o movimento do fandom analisou-se em torno de 3.000 tweets na hashatg e foram identificadas as vozes dos perfis que atingir maior engajamento, as principais problemáticas em relação aos temas, os usuários mais presentes no determinando tempo, o posicionamento dos fãs e as discussões em paralelo.

$\mathrm{Na}$ análise da campanha ArmyHeplthePlanet, notamos a predominância das fanbases dedicadas ao grupo BTS, e o quanto elas são importantes na conversação entre os fãs, visto que são responsáveis por informar e engajar diversos conteúdos que o grupo está envolvido. Em relação as problemáticas envolvidas, os temas se dividiram entre: informações sobre a campanha, notícias sobre a situação da floresta Amazônica diante as queimadas e apoio e suporte do fandom "Army" em todo o mundo, que se solidarizaram com a causa e ajudaram o fandom brasileiro a dar engajamento em suas mensagens. Além disso, percebemos que os perfis de fãs estrangeiros se destacaram como replicadores de conteúdo, o que muitas vezes ajudou ainda os fãs brasileiros a popularizar a campanha. Sendo assim, analisamos como acontece a conversação entre os fãs a respeito de um dos seus vários projetos ligados a causas sociais, e como eles se unem para que o maior número de pessoas se mobilize e contribua.

Tendo em vista os apontamentos obtidos na análise, percebemos que as redes sociais funcionam principalmente como um espaço de interação e engajamento. $\mathrm{O}$ movimento e as atividades realizadas pelo fandom brasileiro do grupo BTS são inúmeras e grande parte delas são sempre destaque entre os assuntos mais comentados Twitter, além de virar notícias em vários jornais. Constatamos que os fãs utilizam o Twitter como espaço de informação, divulgação e também para promover o ativismo com causas sociais. Pela análise notamos o empenho dos fãs e o forte laço em suas relações ao não medir esforços quando o assunto é contribuir em mobilizações sociais ou se dedicar a quaisquer assuntos em relação ao grupo.

Percebemos, também, que o ativismo digital promovido pelo fandom ressignifica outros espaços transformando-se em uma participação política e cívica no seio da comunidade ao promoverem iniciativas de plantações de mudas de árvores pelo país. Como argumenta Jenkins (2009) a cultura da participação pode funcionar como espaço nos quais competências cívicas são impulsionadas e cultivadas.

Por fim, diante da grande produção de conteúdos do Twitter, essa pesquisa não teve como intuito o retrato exato em relação as tags na rede, mas sim, propor uma nova forma de análise através da metodologia da Análise Crítica (ROGERS, 2018). 


\section{REFERÊNCIAS}

ARAÚJO, Ronaldo Ferreira. Marketing científico digital e métricas alternativas para periódicos: da visibilidade ao engajamento. Perspectivas em Ciência da Informação, v. 20, n. 3, p. 67-84, 2015. Disponível em: encurtador.com.br/cevE1. Acesso em: 10 jun. 2019.

ARAÚJO, Willian Fernandes. Ciberativismo: levantamento do estado da arte na pesquisa no Brasil. In: V Simpósio Nacional da ABCiber. Anais [...]. Florianópolis, 2011. Disponível em: http://abciber.org.br/simposio2011/anais/Trabalhos/artigos/Eixo\%207/10.E7/193-300-1RV.pdf. Acesso em: 28 abr. 2019.

BRUNS, Axel; BURGESS, Jean. The use of Twitter hashtags in the formation of ad hoc publics. In: European Consortium for Political Communication Conference. 2011. Disponível em:

http://snurb.info/files/2011/The\%20Use\%20of\%20Twitter\%20Hashtags\%20in\%20the\%20Formati on\%20of\%20Ad\%20Hoc\%20Publics\%20(final).pdf. Acesso em: 06 jun.2019.

CURI, Pedro. Entre fanarts, fanfictions e fanfilms: o consumo dos fãs gerando uma nova cultura. In: ENCONTRO DE ESTUDOS MULTIDISCIPLINARES EM CULTURA, 6, 2010, Salvador. Anais [...]. Bahia: UFBA, 2010. Disponível em: http://www.cult.ufba.br/wordpress/24831.pdf. Acesso em: 14 abr. 2019.

DINIZ, Iara Gabriela Faleiro; CALEIRO, Maurício. Web 2.0 e ciberativismo: O poder das redes na difusão de movimentos sociais. Revista Cientifica do Departamento de Comunicação Social da UFMA, São Luís - MA, Janeiro/Junho de 2011 - Ano XIX - No 8. Disponível em: http://migre.me/eelOL. Acesso em: 14 abr. 2019.

JENKIS, Henry. Cultura da Convergência. São Paulo: Editora Aleph, 2009.

JENKIS, Henry; GREEN, Joshua; FORD, Sam. Cultura da conexão: criando valor e significado por meio da mídia propagável. São Paulo: Editora Aleph, 2014.

MARTINO, Luís Mauro Sá. Teoria das mídias digitais. Brasil: Editora Vozes, 2014.

MONTARDO, Sandra Portella; ARÁUJO, Willian. Performance e práticas de consumo online: ciberativismo em sites de redes sociais. Revista Famecos. Porto Alegre, v. 20, n. 2, 2013. Disponível em:

http://revistaseletronicas.pucrs.br/ojs/index.php/revistafamecos/article/view/13078/10020 .Acesso em: 28 abr. 2019.

ODORICO, Nayana Franklyn. Ativismo Digital: Engajamento no ciberespaço. In: IX Simpósio Nacional da ABCiber. Anais [...]. São Paulo, 2016. Disponível em: http://abciber.org.br/anaiseletronicos/wpcontent/uploads/2016/trabalhos/ativismo_digital_engajamento_no_ciberespaco_nayana_fran k lin_odorico.pdf. Acesso em: 28 abr. 2019.

RECUERO, Raquel. Curtir, compartilhar, comentar: trabalho de face, conversação e redes sociais no Facebook. Verso e Reverso, v. 28, n. 68, p. 114-124, 2014. Disponível 
em:http://revistas.unisinos.br/index.php/versoereverso/article/view/ver.2014.28.68.06.Ac esso em: 10 jun. 2019.

RECUERO, Raquel; ZAGO, Gabriela. Em busca das "redes que importam": redes sociais e capital social no Twitter. Líbero, São Paulo, v.12, n.24, p. 81-94, 2009.

ROGERS, Richard. Otherwise Engaged: social media from vanity metrics to critical analytics. In: International Journal of Communication, 12, p.450-472, 2018. Disponível em:

https://www.researchgate.net/publication/322369349_Otherwise_Engaged_Social_Media_fr om_Vanity_Metrics_to_Critical_Analytics. Acesso em: 25 mai. 2019.

ZANETTI, Daniela. A cultura do compartilhamento e a reprodutibilidade dos conteúdos.

Ciberlegenda, Rio de Janeiro, n. 25, p. 60-70, 2011.

Original recebido em: 26 de maio de 2020

Aceito para publicação em: 22 de agosto de 2021

\section{Carlos Renan Samuel Sanchotene}

Professor dos cursos de Jornalismo e Publicidade e Propaganda (UEMG). Pós-doutor em Comunicação (UFSM). Doutor em Comunicação e Cultura Contemporâneas (UFBA). Mestre em Ciências da Comunicação (UNISINOS). Pesquisador Líder no Grupo de Pesquisa CNPq: Comunicação e Mídias Digitais. Jornalista graduada pela Universidade do Estado de Minas Gerais (UEMG).

\section{(®) $\odot \odot$}

Esta obra está licenciada com uma Licença

Creative Commons Atribuição-NãoComercial-CompartilhaIgual 4.0 Internacional 